\title{
Watermarking Digital Image Using Fuzzy Matrix Compositions and Rough Set
}

\author{
Sharbani Bhattacharya \\ Associate Professor (IT), \\ IEC College of Engineering \& Technology, Greater Noida , India
}

\begin{abstract}
Watermarking is done in digital images for authentication and to restrict its unauthorized usages. Watermarking is sometimes invisible and can be extracted only by authenticated party. Encrypt a text or information by public private key from two fuzzy matrix and embed it in image as watermark. In this paper we proposed two fuzzy compositions Product-Mod-Minus, and Compliment-Product-Minus. Embedded watermark using Fuzzy Rough set created from fuzzy matrix compositions.
\end{abstract}

Keywords-Fuzzy Product-Mod-Minus Matrix; Fuzzy Compliment-Product-Minus Matrix; Fuzzy Rough set; Watermarking; Encrypting

\section{INTRODUCTION}

Watermarking in digital image is for authentication and restricting it for unauthorized usages. Videos and other digital contents are used often by unauthorized users. Watermarking and fingerprinting are used to find the point of leakage or user who allowed unauthorized use of the digital content. The watermarking can be visible or invisible. Visible watermarking is used for authentication whereas invisible watermarking is used for restricting unauthorized usages. The Robustness of watermark depends upon its tolerance towards its tamper or delete. It should be identified and extracted to receive information by authorized party. The amount of embedding of information in a digital content without getting identified is its Capacity.

\section{ENCRYPTION METHODS}

Cryptography is an art of converting a message into cipher text and send to the destination. The authorized person can decipher the text and retrieve the original message. This technology is used from very beginning of the civilization. As the days go by we have new and recent technology coming up so the cryptographic methods are also changing. Prior we had texts which are converted into cipher text by using some notion that A should read as B and B should be read as C and so on. Doing this we get a cipher text which is not easily readable unless one knows the conversion method. Public Key and Private Key method is used for cryptography. There are many methods like RSA, DES, Diffie-Hellmann and etc. for cryptography. In 1976, Martin Hellman, a professor at Stanford University, and Whitfield Diffie, a graduate student, introduced the concept of asymmetric or public key cryptography. We will use here public key and private key as two fuzzy matrices. One matrix is given by user is public key and second fuzzy matrix is randomly chosen from the database to give resultant private key fuzzy matrix.

\section{FUZZY MATRIX COMPOSITIONS}

The Fuzzy rules are consisting of rules defined on fuzzy set. Fuzzy set are acquired from Crisp Set using membership function. This process is known as fuzzification. Converting fuzzy set to Crisp set is called defuzzification. Fuzzy set has members which can take values 0 to 1 . Thus, Fuzzy set A values like $A=\{0.1 / x 1,0.3 / x 2,0.4 / x 3\}$. This means 0.1 is membership value of $x 1$ in set $A, 0.3$ membership value for $x 2$ and 0.4 membership value for $\mathrm{x} 3$ in set $\mathrm{A}$. Here, we will be using fuzzy matrix for encryption of the text/file which is to be used for watermarking. The encrypted file is then embedded into digital image using Fuzzy Rough sets. Fuzzy Rough set is $\mathrm{P}=\{\inf (\mathrm{A}), \operatorname{Sup}(\mathrm{A})\}$ where $\mathrm{A}$ is the Fuzzy set. $\operatorname{Inf}(\mathrm{A})$ is 0.1 i.e. lower bound of set Fuzzy $\mathrm{A}$ and $\operatorname{Sup}(\mathrm{A})$ is 0.4 i.e. upper bound of set Fuzzy A. The encrypted watermark can be extracted from the digital image in unified format. The unified format is then decrypted using algorithm. The paper proposes two fuzzy matrix composition Fuzzy Product-ModMinus composition and Fuzzy Compliment-Product-Minus composition. Embedding will be done creating Fuzzy Rough set from these two new compositions, published Fuzzy MaxMod-Minus composition and Fuzzy Compliment-Sum-Minus composition [29] and the Fuzzy Max-Min composition.

\section{A. Fuzzy Product-Mod-Minus Composition}

The Fuzzy Product-Mod-Minus composition is proposed rule consisting of following method. Let A, B and C are fuzzy set with $\mathrm{A}(\mathrm{x} 1, \mathrm{x} 2), \mathrm{B}(\mathrm{y} 1, \mathrm{y} 2)$ and $\mathrm{C}(\mathrm{z} 1, \mathrm{z} 2)$. Let us say,

$$
\begin{aligned}
& \mu_{\mathrm{A}, \mathrm{B}}(\mathrm{x} 1, \mathrm{y} 1)=0.2 \\
& \mu_{\mathrm{A}, \mathrm{B}}(\mathrm{x} 1, \mathrm{y} 2)=0.3 \\
& \mu_{\mathrm{A}, \mathrm{B}}(\mathrm{x} 2, \mathrm{y} 1)=0.2 \\
& \mu_{\mathrm{A}, \mathrm{B}}(\mathrm{x} 2, \mathrm{y} 2)=0.4 \\
& \mu_{\mathrm{B}, \mathrm{C}}(\mathrm{y} 1, \mathrm{z} 1)=0.3 \\
& \mu_{\mathrm{B}, \mathrm{C}}(\mathrm{y} 1, \mathrm{z} 2)=0.5 \\
& \mu_{\mathrm{B}, \mathrm{C}}(\mathrm{y} 2, \mathrm{z} 1)=0.2 \\
& \mu_{\mathrm{B}, \mathrm{C}}(\mathrm{y} 2, \mathrm{z} 2)=0.2
\end{aligned}
$$


The matrix of $\mu_{\mathrm{A}, \mathrm{C}}$ is

$\mu_{\mathrm{A}, \mathrm{C}}(\mathrm{x} 1, \mathrm{z} 1)=\left\{\left|\mu_{\mathrm{A}, \mathrm{B}}(\mathrm{x} 1, \mathrm{y} 1)-\mu_{\mathrm{B}, \mathrm{C}}(\mathrm{y} 1, \mathrm{z} 1)\right|^{*} \mid \mu_{\mathrm{A}, \mathrm{B}}(\mathrm{x} 1, \mathrm{y} 2)-\mu_{\mathrm{B}, \mathrm{C}}\right.$ $(\mathrm{y} 2, \mathrm{z} 1) \mid\}=0.01$

$\mu_{\mathrm{A}, \mathrm{C}}(\mathrm{x} 1, \mathrm{z} 2)=\left\{\left|\mu_{\mathrm{A}, \mathrm{B}}(\mathrm{x} 1, \mathrm{y} 1)-\mu_{\mathrm{B}, \mathrm{C}}(\mathrm{y} 1, \mathrm{z} 2)\right| * \mid \mu_{\mathrm{A}, \mathrm{B}}(\mathrm{x} 1, \mathrm{y} 2)-\mu_{\mathrm{B}, \mathrm{C}}\right.$ $(\mathrm{y} 2, \mathrm{z} 2) \mid\}=0.03$

$\mu_{\mathrm{A}, \mathrm{C}}(\mathrm{x} 2, \mathrm{z} 1)=\left\{\left|\mu_{\mathrm{A}, \mathrm{B}}(\mathrm{x} 2, \mathrm{y} 1)-\mu_{\mathrm{B}, \mathrm{C}}(\mathrm{y} 1, \mathrm{z} 1)\right|^{*} \mid \mu_{\mathrm{A}, \mathrm{B}}(\mathrm{x} 2, \mathrm{y} 2)-\right.$ $\left.\mu_{\mathrm{B}, \mathrm{C}}(\mathrm{y} 2, \mathrm{z} 1) \mid\right\}=0.02$

$\mu_{\mathrm{A}, \mathrm{C}}(\mathrm{x} 2, \mathrm{z} 2)=\left\{\left|\mu_{\mathrm{A}, \mathrm{B}}(\mathrm{x} 2, \mathrm{y} 1)-\mu_{\mathrm{B}, \mathrm{C}}(\mathrm{y} 1, \mathrm{z} 2)\right|^{*} \mid \mu_{\mathrm{A}, \mathrm{B}}(\mathrm{x} 2, \mathrm{y} 2)-\mu_{\mathrm{B}, \mathrm{C}}\right.$ $(\mathrm{y} 2, \mathrm{z} 2) \mid\}=0.06$

\section{B. Fuzzy Compliment-Product-Minus Composition}

The Fuzzy Compliment-Product-Minus composition is proposed rule consisting of following method. Let $\mathrm{A}, \mathrm{B}$ and $\mathrm{C}$ are fuzzy set with $\mathrm{A}(\mathrm{x} 1, \mathrm{x} 2), \mathrm{B}(\mathrm{y} 1, \mathrm{y} 2)$ and $\mathrm{C}(\mathrm{z} 1, \mathrm{z} 2)$. Let us say,

$$
\begin{aligned}
& \mu_{\mathrm{A}, \mathrm{B}}(\mathrm{x} 1, \mathrm{y} 1)=0.2 \\
& \mu_{\mathrm{A}, \mathrm{B}}(\mathrm{x} 1, \mathrm{y} 2)=0.3 \\
& \mu_{\mathrm{A}, \mathrm{B}}(\mathrm{x} 2, \mathrm{y} 1)=0.2 \\
& \mu_{\mathrm{A}, \mathrm{B}}(\mathrm{x} 2, \mathrm{y} 2)=0.4 \\
& \mu_{\mathrm{B}, \mathrm{C}}(\mathrm{y} 1, \mathrm{z} 1)=0.3 \\
& \mu_{\mathrm{B}, \mathrm{C}}(\mathrm{y} 1, \mathrm{z} 2)=0.5 \\
& \mu_{\mathrm{B}, \mathrm{C}}(\mathrm{y} 2, \mathrm{z} 1)=0.2 \\
& \mu_{\mathrm{B}, \mathrm{C}}(\mathrm{y} 2, \mathrm{z} 2)=0.2
\end{aligned}
$$

The matrix of $\mu_{\mathrm{A}, \mathrm{C}}$ is

$\mu_{\mathrm{A}, \mathrm{C}}(\mathrm{x} 1, \mathrm{z} 1)=\mid 1-\left\{\left|\mu_{\mathrm{A}, \mathrm{B}}(\mathrm{x} 1, \mathrm{y} 1)-\mu_{\mathrm{B}, \mathrm{C}}(\mathrm{y} 1, \mathrm{z} 1)\right|^{*} \mid \mu_{\mathrm{A}, \mathrm{B}}(\mathrm{x} 1, \mathrm{y} 2)-\right.$ $\left.\mu_{\mathrm{B}, \mathrm{C}}(\mathrm{y} 2, \mathrm{z} 1) \mid\right\} \mid=0.99$

$\mu_{\mathrm{A}, \mathrm{C}}(\mathrm{x} 1, \mathrm{z} 2)=\mid 1-\left\{\left|\mu_{\mathrm{A}, \mathrm{B}}(\mathrm{x} 1, \mathrm{y} 1)-\mu_{\mathrm{B}, \mathrm{C}}(\mathrm{y} 1, \mathrm{z} 2)\right| * \mid \mu_{\mathrm{A}, \mathrm{B}}(\mathrm{x} 1, \mathrm{y} 2)-\right.$ $\left.\mu_{\mathrm{B}, \mathrm{C}}(\mathrm{y} 2, \mathrm{z} 2) \mid\right\} \mid=0.97$

$\mu_{\mathrm{A}, \mathrm{C}}(\mathrm{x} 2, \mathrm{z} 1)=\mid 1-\left\{\left|\mu_{\mathrm{A}, \mathrm{B}}(\mathrm{x} 2, \mathrm{y} 1)-\mu_{\mathrm{B}, \mathrm{C}}(\mathrm{y} 1, \mathrm{z} 1)\right| * \mid \mu_{\mathrm{A}, \mathrm{B}}(\mathrm{x} 2, \mathrm{y} 2)-\right.$ $\left.\mu_{\mathrm{B}, \mathrm{C}}(\mathrm{y} 2, \mathrm{z} 1) \mid\right\} \mid=0.98$

$\mu_{\mathrm{A}, \mathrm{C}}(\mathrm{x} 2, \mathrm{z} 2)=\mid 1-\left\{\left|\mu_{\mathrm{A}, \mathrm{B}}(\mathrm{x} 2, \mathrm{y} 1) \quad-\mu_{\mathrm{B}, \mathrm{C}}(\mathrm{y} 1, \mathrm{z} 2)\right|^{*} \mid \mu_{\mathrm{A}, \mathrm{B}}(\mathrm{x} 2, \mathrm{y} 2)-\right.$ $\left.\mu_{\mathrm{B}, \mathrm{C}}(\mathrm{y} 2, \mathrm{z} 2) \mid\right\} \mid=0.94$

\section{Fuzzy Max-Mod-Minus Composition}

The Fuzzy Max-Mod-Minus composition rule [29] is consisting of following method. Let $\mathrm{A}, \mathrm{B}$ and $\mathrm{C}$ are fuzzy set with $\mathrm{A}(\mathrm{x} 1, \mathrm{x} 2), \mathrm{B}(\mathrm{y} 1, \mathrm{y} 2)$ and $\mathrm{C}(\mathrm{z} 1, \mathrm{z} 2)$. Let us say,

$\mu_{\mathrm{A}, \mathrm{B}}(\mathrm{x} 1, \mathrm{y} 1)=0.2$
$\mu_{\mathrm{A}, \mathrm{B}}(\mathrm{x} 1, \mathrm{y} 2)=0.3$

$\mu_{\mathrm{A}, \mathrm{B}}(\mathrm{x} 2, \mathrm{y} 1)=0.2$

$\mu_{\mathrm{A}, \mathrm{B}}(\mathrm{x} 2, \mathrm{y} 2)=0.4$

$\mu_{\mathrm{B}, \mathrm{C}}(\mathrm{y} 1, \mathrm{z} 1)=0.3$

$\mu_{\mathrm{B}, \mathrm{C}}(\mathrm{y} 1, \mathrm{z} 2)=0.5$

$\mu_{\mathrm{B}, \mathrm{C}}(\mathrm{y} 2, \mathrm{z} 1)=0.2$

$\mu_{\mathrm{B}, \mathrm{C}}(\mathrm{y} 2, \mathrm{z} 2)=0.2$

The matrix of $\mu_{\mathrm{A}, \mathrm{C}}$ is

$\mu_{\mathrm{A}, \mathrm{C}}(\mathrm{x} 1, \mathrm{z} 1)=\max \left\{\left|\mu_{\mathrm{A}, \mathrm{B}}(\mathrm{x} 1, \mathrm{y} 1)-\mu_{\mathrm{B}, \mathrm{C}}(\mathrm{y} 1, \mathrm{z} 1)\right|, \mid \mu_{\mathrm{A}, \mathrm{B}}(\mathrm{x} 1, \mathrm{y} 2)-\right.$ $\left.\mu_{\mathrm{B}, \mathrm{C}}(\mathrm{y} 2, \mathrm{z} 1) \mid\right\}=0.1$

$\mu_{\mathrm{A}, \mathrm{C}}(\mathrm{x} 1, \mathrm{z} 2)=\max \left\{\left|\mu_{\mathrm{A}, \mathrm{B}}(\mathrm{x} 1, \mathrm{y} 1)-\mu_{\mathrm{B}, \mathrm{C}}(\mathrm{y} 1, \mathrm{z} 2)\right|, \mid \mu_{\mathrm{A}, \mathrm{B}}(\mathrm{x} 1, \mathrm{y} 2)-\right.$ $\left.\mu_{\mathrm{B}, \mathrm{C}}(\mathrm{y} 2, \mathrm{z} 2) \mid\right\}=0.3$

$\mu_{\mathrm{A}, \mathrm{C}}(\mathrm{x} 2, \mathrm{z} 1)=\max \left\{\left|\mu_{\mathrm{A}, \mathrm{B}}(\mathrm{x} 2, \mathrm{y} 1), \mu_{\mathrm{B}, \mathrm{C}}(\mathrm{y} 1, \mathrm{z} 1)\right|, \mid \mu_{\mathrm{A}, \mathrm{B}}(\mathrm{x} 2, \mathrm{y} 2)-\right.$ $\left.\mu_{\mathrm{B}, \mathrm{C}}(\mathrm{y} 2, \mathrm{z} 1) \mid\right\}=0.2$

$\mu_{\mathrm{A}, \mathrm{C}}(\mathrm{x} 2, \mathrm{z} 2)=\max \left\{\left|\mu_{\mathrm{A}, \mathrm{B}}(\mathrm{x} 2, \mathrm{y} 1), \mu_{\mathrm{B}, \mathrm{C}}(\mathrm{y} 1, \mathrm{z} 2)\right|, \mid \mu_{\mathrm{A}, \mathrm{B}}(\mathrm{x} 2, \mathrm{y} 2)-\right.$ $\left.\mu_{\mathrm{B}, \mathrm{C}}(\mathrm{y} 2, \mathrm{z} 2) \mid\right\}=0.3$

\section{Fuzzy Compliment-Sum-Minus Composition}

The Fuzzy Compliment-Sum-Minus composition [29] is consisting of following method. Let $\mathrm{A}, \mathrm{B}$ and $\mathrm{C}$ are fuzzy set with $\mathrm{A}(\mathrm{x} 1, \mathrm{x} 2), \mathrm{B}(\mathrm{y} 1, \mathrm{y} 2)$ and $\mathrm{C}(\mathrm{z} 1, \mathrm{z} 2)$. Let us say,

$\mu_{\mathrm{A}, \mathrm{B}}(\mathrm{x} 1, \mathrm{y} 1)=0.2$

$\mu_{\mathrm{A}, \mathrm{B}}(\mathrm{x} 1, \mathrm{y} 2)=0.3$

$\mu_{\mathrm{A}, \mathrm{B}}(\mathrm{x} 2, \mathrm{y} 1)=0.2$

$\mu_{\mathrm{A}, \mathrm{B}}(\mathrm{x} 2, \mathrm{y} 2)=0.4$

$\mu_{\mathrm{B}, \mathrm{C}}(\mathrm{y} 1, \mathrm{z} 1)=0.3$

$\mu_{\mathrm{B}, \mathrm{C}}(\mathrm{y} 1, \mathrm{z} 2)=0.5$

$\mu_{\mathrm{B}, \mathrm{C}}(\mathrm{y} 2, \mathrm{z} 1)=0.2$

$\mu_{\mathrm{B}, \mathrm{C}}(\mathrm{y} 2, \mathrm{z} 2)=0.2$

The matrix of $\mu_{\mathrm{A}, \mathrm{C}}$ is

$\mu_{\mathrm{A}, \mathrm{C}}(\mathrm{x} 1, \mathrm{z} 1)=\mid 1-\left\{\left|\mu_{\mathrm{A}, \mathrm{B}}(\mathrm{x} 1, \mathrm{y} 1)-\mu_{\mathrm{B}, \mathrm{C}}(\mathrm{y} 1, \mathrm{z} 1)\right|+\mid \mu_{\mathrm{A}, \mathrm{B}}(\mathrm{x} 1, \mathrm{y} 2)-\right.$ $\left.\mu_{\mathrm{B}, \mathrm{C}}(\mathrm{y} 2, \mathrm{z} 1) \mid\right\} \mid=0.8$

$\mu_{\mathrm{A}, \mathrm{C}}(\mathrm{x} 1, \mathrm{z} 2)=\mid 1-\left\{\left|\mu_{\mathrm{A}, \mathrm{B}}(\mathrm{x} 1, \mathrm{y} 1)-\mu_{\mathrm{B}, \mathrm{C}}(\mathrm{y} 1, \mathrm{z} 2)\right|+\mid \mu_{\mathrm{A}, \mathrm{B}}(\mathrm{x} 1, \mathrm{y} 2)-\right.$ $\left.\mu_{\mathrm{B}, \mathrm{C}}(\mathrm{y} 2, \mathrm{z} 2) \mid\right\} \mid=0.6$ 
$\mu_{\mathrm{A}, \mathrm{C}}(\mathrm{x} 2, \mathrm{z} 1)=\mid 1-\left\{\left|\mu_{\mathrm{A}, \mathrm{B}}(\mathrm{x} 2, \mathrm{y} 1)-\mu_{\mathrm{B}, \mathrm{C}}(\mathrm{y} 1, \mathrm{z} 1)\right|+\mid \mu_{\mathrm{A}, \mathrm{B}}(\mathrm{x} 2, \mathrm{y} 2)-\right.$ $\left.\mu_{\mathrm{B}, \mathrm{C}}(\mathrm{y} 2, \mathrm{z} 1) \mid\right\} \mid=0.7$

$\mu_{\mathrm{A}, \mathrm{C}}(\mathrm{x} 2, \mathrm{z} 2)=\mid 1-\left\{\left|\mu_{\mathrm{A}, \mathrm{B}}(\mathrm{x} 2, \mathrm{y} 1)-\mu_{\mathrm{B}, \mathrm{C}}(\mathrm{y} 1, \mathrm{z} 2)\right|+\mid \mu_{\mathrm{A}, \mathrm{B}}(\mathrm{x} 2, \mathrm{y} 2)-\right.$ $\left.\mu_{\mathrm{B}, \mathrm{C}}(\mathrm{y} 2, \mathrm{z} 2) \mid\right\} \mid=0.5$

\section{E. Fuzzy Max-Min Composition}

The Fuzzy Max-Min composition is consisting of following method. Let $\mathrm{A}, \mathrm{B}$ and $\mathrm{C}$ are fuzzy set with $\mathrm{A}(\mathrm{x} 1$, $\mathrm{x} 2), \mathrm{B}(\mathrm{y} 1, \mathrm{y} 2)$ and $\mathrm{C}(\mathrm{z} 1, \mathrm{z} 2)$.

Let us say,

$$
\begin{aligned}
& \mu_{\mathrm{A}, \mathrm{B}}(\mathrm{x} 1, \mathrm{y} 1)=0.2 \\
& \mu_{\mathrm{A}, \mathrm{B}}(\mathrm{x} 1, \mathrm{y} 2)=0.3 \\
& \mu_{\mathrm{A}, \mathrm{B}}(\mathrm{x} 2, \mathrm{y} 1)=0.2 \\
& \mu_{\mathrm{A}, \mathrm{B}}(\mathrm{x} 2, \mathrm{y} 2)=0.4 \\
& \mu_{\mathrm{B}, \mathrm{C}}(\mathrm{y} 1, \mathrm{z} 1)=0.3 \\
& \mu_{\mathrm{B}, \mathrm{C}}(\mathrm{y} 1, \mathrm{z} 2)=0.5 \\
& \mu_{\mathrm{B}, \mathrm{C}}(\mathrm{y} 2, \mathrm{z} 1)=0.2 \\
& \mu_{\mathrm{B}, \mathrm{C}}(\mathrm{y} 2, \mathrm{z} 2)=0.2
\end{aligned}
$$

The matrix of $\mu_{\mathrm{A}, \mathrm{C}}$ is

$\mu_{\mathrm{A}, \mathrm{C}}(\mathrm{x} 1, \mathrm{z} 1)=\max \left\{\min \left[\mu_{\mathrm{A}, \mathrm{B}}(\mathrm{x} 1, \mathrm{y} 1), \mu_{\mathrm{B}, \mathrm{C}}(\mathrm{y} 1, \mathrm{z} 1)\right], \min \left[\mu_{\mathrm{A}, \mathrm{B}}\right.\right.$ $\left.\left.(\mathrm{x} 1, \mathrm{y} 2), \mu_{\mathrm{B}, \mathrm{C}}(\mathrm{y} 2, \mathrm{z} 1)\right]\right\}=0.2$

$\mu_{\mathrm{A}, \mathrm{C}}(\mathrm{x} 1, \mathrm{z} 2)=\max \left\{\min \left[\mu_{\mathrm{A}, \mathrm{B}}(\mathrm{x} 1, \mathrm{y} 1), \mu_{\mathrm{B}, \mathrm{C}}(\mathrm{y} 1, \mathrm{z} 2)\right], \min \left[\mu_{\mathrm{A}, \mathrm{B}}\right.\right.$ $\left.\left.(\mathrm{x} 1, \mathrm{y} 2), \mu_{\mathrm{B}, \mathrm{C}}(\mathrm{y} 2, \mathrm{z} 2)\right]\right\}=0.2$

$\mu_{\mathrm{A}, \mathrm{C}}(\mathrm{x} 2, \mathrm{z} 1)=\max \left\{\min \left[\mu_{\mathrm{A}, \mathrm{B}}(\mathrm{x} 2, \mathrm{y} 1), \mu_{\mathrm{B}, \mathrm{C}}(\mathrm{y} 1, \mathrm{z} 1)\right], \min [\right.$ $\left.\left.\mu_{\mathrm{A}, \mathrm{B}}(\mathrm{x} 2, \mathrm{y} 2), \mu_{\mathrm{B}, \mathrm{C}}(\mathrm{y} 2, \mathrm{z} 1)\right]\right\}=0.2$

$\mu_{\mathrm{A}, \mathrm{C}}(\mathrm{x} 2, \mathrm{z} 2)=\max \left\{\min \left[\mu_{\mathrm{A}, \mathrm{B}}(\mathrm{x} 2, \mathrm{y} 1), \mu_{\mathrm{B}, \mathrm{C}}(\mathrm{y} 1, \mathrm{z} 2)\right], \min \left[\mu_{\mathrm{A}, \mathrm{B}}\right.\right.$ $\left.\left.(\mathrm{x} 2, \mathrm{y} 2), \mu_{\mathrm{B}, \mathrm{C}}(\mathrm{y} 2, \mathrm{z} 2)\right]\right\}=0.2$

\section{PROPOSED Public KeY- Private KeY ENCRYPTION ALGORITHM}

The encryption is done using fuzzy set values. The fuzzy rules are then used to decrypt the context. The public key is given by user is a fuzzy matrix. There is also a database consisting of fuzzy matrices. The public key given by user and fuzzy matrix from database is chosen randomly and Fuzzy Compliment-Product-Minus composition is used get resultant fuzzy matrix. The encryption is done using this fuzzy matrix. The encryption algorithm has following steps

Step 1: User chooses one Fuzzy matrix appropriate for encryption. It is public key.
Step2: Select one fuzzy matrix from database.

Step3: Find the Fuzzy Compliment-Product-Minus matrix.

Step3: Generate random number using Fuzzy ComplimentProduct-Minus matrix.

Step4: Retrieve the encrypted text/files.

There are various ways of encryption. Here, 2X2 fuzzy matrices are used to obtain Compliment-Product-Minus of the fuzzy matrix. The text/files is encrypted by ComplimentProduct-Minus of the fuzzy matrix.

\section{PROPOSED DECRYPTION ALGORITHM}

Decryption algorithm is used decrypt the cipher text file. The following algorithm is used-

Step1: Collect the encrypted four parts from four different embedded region of image and combine to for one file.

Step2: Use private key fuzzy matrix key for decryption.

Step3: Retrieve the original file.

\section{EMBEDDING THE WATERMARK}

The watermark embedding process is done by inserting the encrypted watermark at appropriate place. Encrypted file is divided into one, two or more parts say b1, b2 and b3.

The three encrypted files are embedded in digital image as watermark using appropriate fuzzy rule. There are many fuzzy matrix compositions like Max-Min, Max-Max, Min-Max, Max-Product, Min-Product composition and etc. The two fuzzy matrices obtained are first used for encrypting watermark. Now for embedding the various compositions of fuzzy matrices are obtained. Using five fuzzy matrix compositions of Section II we will create Fuzzy Rough set $\mathrm{P} 11, \mathrm{P} 12, \mathrm{P} 21$ and P22. The encrypted three parts of file are inserted at three places of digital image using the most suitable Fuzzy Rough set say P21 and P22. Fig. 4, 5 and 6 shows watermarked images using the fuzzy matrix composition and Fuzzy Rough set.

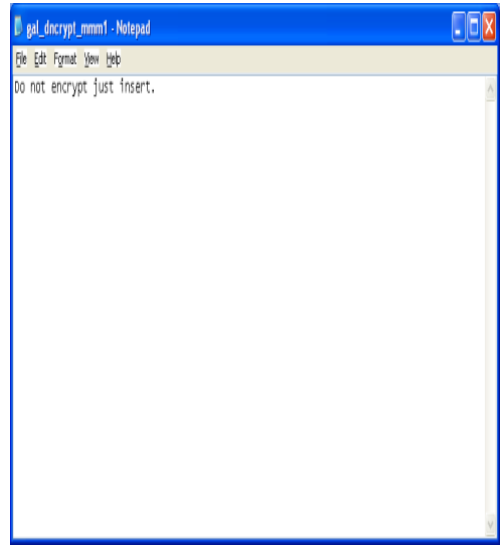

Fig. 1. Text file 

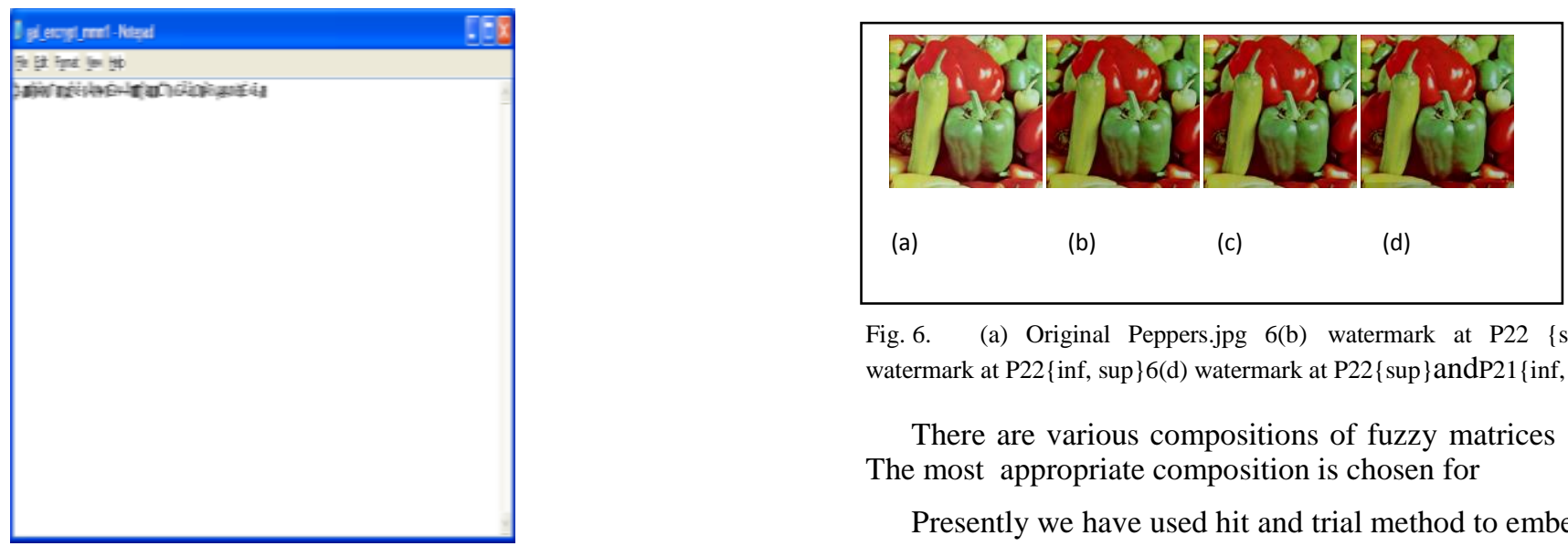

Fig. 6. (a) Original Peppers.jpg 6(b) watermark at P22 \{sup\} 6(c) watermark at P22\{inf, sup\}6(d) watermark at P22\{sup\}andP21 \{inf, sup\}

There are various compositions of fuzzy matrices as said. The most appropriate composition is chosen for

Presently we have used hit and trial method to embed.

Any image can have invisible watermark with fuzzy

Fig. 2. Encrypted Text

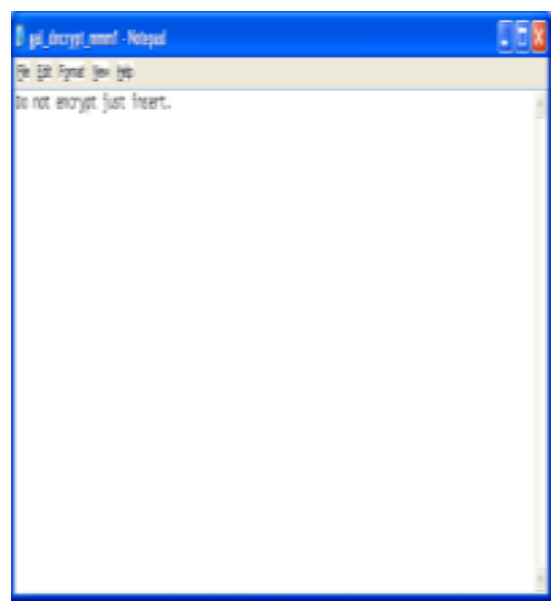

matrix compositions [29]. Next section explains the proposed method of creating Fuzzy Rough set to embed the watermark.

\section{PROPOSED FuZZY ROUGH SET FOR EMBEDDING}

The upper bound and lower bound concept Rough Set (Pawlak 1991) are used in fuzzy logic gives Fuzzy Rough Set. Fuzzy Rough set are two infimum and supremum chosen from fuzzy values. Let us say Fuzzy set $A=\{0.21 / x 1,0.33 / x 2,0.3 / \times 3$ $, 0.4 / \times 4\}$. The set has infimum 0.2 (i.e. lower bound) and supremum is 0.4 (i.e. upper bound) i.e. no element in the set is less than 0.2 and greater than 0.4 respectively. The Fuzzy Rough set is $\mathrm{P}=\{0.2,0.4\}$. Two fuzzy matrices are obtained one from database and one by user. From these two fuzzy matrices using five fuzzy matrix compositions of Section II we obtain five Fuzzy matrices i.e. Fuzzy Max-Mod-Minus matrix, Fuzzy Max-Product-Minus matrix, Fuzzy Max-Min matrix, Fuzzy Compliment-Sum-Minus matrix and Fuzzy Compliment-Product-Minus matrix. We create Fuzzy Rough set from five fuzzy matrices. Let us denote

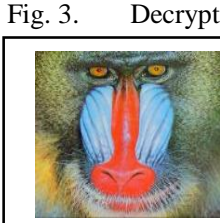

(a)

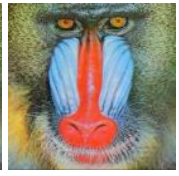

(b)

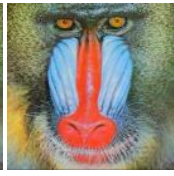

(c)

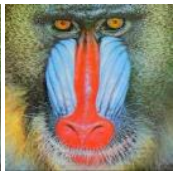

(d)

Fig. 4. (a) Original baboon.jpg 4(b) watermark at P22 \{sup\} 4(c) watermark at P22\{inf, sup\}4(d) watermark at P22\{inf,sup\}and P21\{sup\}

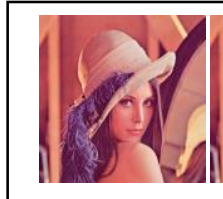

(a)

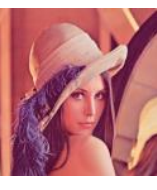

(b) (c)

(d)

Fig. 5. (a) Original lena.jpg 5(b) watermark at P22 \{sup\} 5(c) watermark at P22 \{inf, sup 5 (d) watermark at P22\{inf, sup\}and P21\{sup\}

$\mathrm{f}_{1}=\mu_{\mathrm{A}, \mathrm{C}}(\mathrm{x} 1, \mathrm{z} 1)$,

$\mathrm{f}_{2}=\mu_{\mathrm{A}, \mathrm{C}}(\mathrm{x} 1, \mathrm{z} 2)$,

$\mathrm{f}_{3}=\mu_{\mathrm{A}, \mathrm{C}}(\mathrm{x} 2, \mathrm{z} 1)$,

$\mathrm{f}_{4}=\mu_{\mathrm{A}, \mathrm{C}}(\mathrm{x} 2, \mathrm{z} 2)$.

We get $f_{1}, f_{2}, f_{3}$ and $f_{4}$ fuzzy matrix elements from all five above said fuzzy matrix compositions.

We denote $f_{1 M P M}, f_{1 M M}, f_{1 C S M}, f_{1 C P M}$ and $f_{1 M M M}$ for $\mu_{A, C}$ $(\mathrm{x} 1, \mathrm{z} 1)$ of Fuzzy Max-Product-Minus matrix , Fuzzy MaxMin matrix ,Fuzzy Compliment-Sum-Minus matrix ,Fuzzy Compliment-Product-Minus matrix and Fuzzy Max-ModMinus matrix respectively. Similarly, we have $\mathrm{f}_{2 \mathrm{MPM}}, \mathrm{f}_{2 \mathrm{MM}}$, $\mathrm{f}_{2 \mathrm{CSM}} \quad \mathrm{f}_{2 \mathrm{CPM}}$ and $\mathrm{f}_{2 \mathrm{MMM}}$ for $\mu_{\mathrm{A}, \mathrm{C}}(\mathrm{x} 1, \mathrm{z} 2)$ of Fuzzy MaxProduct-Minus matrix , Fuzzy Max-Min matrix ,Fuzzy Compliment-Sum-Minus matrix ,Fuzzy Compliment-ProductMinus matrix and Fuzzy Max-Mod-Minus matrix respectively. We have $\mathrm{f}_{3 M P M}, \mathrm{f}_{3 \mathrm{MM}}, \mathrm{f}_{3 \mathrm{CSM}}, \mathrm{f}_{3 \mathrm{CPM}}$ and $\mathrm{f}_{3 \mathrm{MMM}}$ for $\mu_{\mathrm{A}, \mathrm{C}}(\mathrm{x} 2, \mathrm{z} 1)$ of Fuzzy Max-Product-Minus matrix , Fuzzy Max-Min matrix ,Fuzzy Compliment-Sum-Minus matrix ,Fuzzy Compliment-Product-Minus matrix and Fuzzy Max- 
Mod-Minus matrix respectively. We have $\mathrm{f}_{4 \mathrm{MPM}}, \mathrm{f}_{4 \mathrm{MM}}, \mathrm{f}_{4 \mathrm{CSM}}$ , $\mathrm{f}_{4 \mathrm{CPM}}$ and $\mathrm{f}_{4 \mathrm{MMM}}$ for $\mu_{\mathrm{A}, \mathrm{C}}(\mathrm{x} 2, \mathrm{z} 2)$ of Fuzzy Max-ProductMinus matrix , Fuzzy Max-Min matrix ,Fuzzy ComplimentSum-Minus matrix ,Fuzzy Compliment-Product-Minus matrix and Fuzzy Max-Mod-Minus matrix respectively.

We get fuzzy set $\mathrm{G} 11=\left\{0.2 / \mathrm{f}_{1 \mathrm{MPM}}, 0.8 / \mathrm{f}_{1 \mathrm{MM}}, 0.99 / \mathrm{f}_{1 \mathrm{CSM}}\right.$ $\left., 0.01 / \mathrm{f}_{1 \mathrm{CPM}}, 0.1 / \mathrm{f}_{1 \mathrm{MMM}}\right\}, \mathrm{G} 12=\left\{0.2 / \mathrm{f}_{2 \mathrm{MPM}}, 0.6 / \mathrm{f}_{2 \mathrm{MM}}, 0.98 / \mathrm{f}_{2 \mathrm{CSM}}\right.$ $\left., \quad 0.03 / \mathrm{f}_{2 \mathrm{CPM}}, \quad 0.3 / \mathrm{f}_{2 \mathrm{MMM}}\right\}, \quad \mathrm{G} 21=\left\{0.2 / \mathrm{f}_{3 \mathrm{MPM}}, \quad 0.7 / \mathrm{f}_{3 \mathrm{MM}}\right.$ $\left., 0.97 / \mathrm{f}_{3 \mathrm{CSM}}, 0.02 / \mathrm{f}_{3 \mathrm{CPM}}, 0.2 / \mathrm{f}_{3 \mathrm{MMM}}\right\}$ and $\mathrm{G} 22=\left\{0.2 / \mathrm{f}_{4 \mathrm{MPM}}\right.$ $\left., 0.5 / \mathrm{f}_{4 \mathrm{MM}}, 0.94 / \mathrm{f}_{4 \mathrm{CSM}}, 0.06 / \mathrm{f}_{4 \mathrm{CPM}}, 0.3 / \mathrm{f}_{4 \mathrm{MMM}}\right\}$ from the all five fuzzy composition matrices. Now, Fuzzy Rough set of each G11, G12, G21 and G22 are P11, P12, P21 and P22 i.e. pair of infimum (inf) and supremum (sup). $P 11=\{0.01,0.99\}$ from $\mathrm{G} 11, \mathrm{P} 12=\{0.03,0.98\}$ from $\mathrm{G} 12, \mathrm{P} 21=\{0.02,0.97\}$ from $\mathrm{G} 21$ and $\mathrm{P} 22=\{0.06,0.94\}$ from $\mathrm{G} 22$. We will use these values for embedding watermark at may be at eight points or any four points or three points or so in the image according to our requirement of robustness and invisibility.

Embedding algorithm proposed using Fuzzy Matrices and Rough set

Step1: Get encrypted file and divide it into four or more parts.

Step2: Obtain the two matrices one from user and another from database.

Step3: Obtain the fuzzy matrices using the Fuzzy Max-ModMinus composition, Fuzzy Max-Product-Minus composition, Fuzzy Max-Min composition, Fuzzy Compliment-Sum-Minus composition and Fuzzy Compliment-Product-Minus composition.

Step4: Obtain P11, P12, P21 and P22 Fuzzy Rough set from Fuzzy Max-Mod-Minus matrix, Fuzzy Max-Product-Minus matrix, Fuzzy Max-Min matrix, Fuzzy Compliment-SumMinus matrix and Fuzzy Compliment-Product-Minus matrix.

Step5 : Embed the watermark at points in the image using P11,P12, P21 and P22 Fuzzy Rough set.

We can break into two or more parts the encrypted file and embedded watermark at P11 $\{\inf (\mathrm{G} 11), \sup (\mathrm{G} 11)\}, \mathrm{P} 12$ $\{\inf (\mathrm{G} 12), \sup (\mathrm{G} 12)\}$ and so on. We get eight points where we can embed watermark from four Fuzzy Rough set. We can also use only one Fuzzy Rough set for embedding at one point say at sup or at inf. We have embedded watermark in three images baboon.jpg, lena.jpg and peppers.jpg using Fuzzy Rough set in Figure 4, 5 and 6. We then find the Peak Signal to Noise Ratio of original image and watermarked image Table I. We obtained the results that in most of the cases PSNR are either or less than 30 Decibel. Only in baboon.jpg when we have inserted at three points have PSNR 42 Decibel. Thus, results show that there is very less deterioration of quality of image (PSNR 30-50) and we also have robustness of watermark. The PSNR 0 means no difference in quality between original and watermarked image.
TABLE I. PSNR OF ORIGINAL AND WATERMARKED IMAGE.

\begin{tabular}{|l|l|l|}
\hline Original Image & $\begin{array}{l}\text { Fuzzy rough set used for } \\
\text { insertion of watermark in } \\
\text { image }\end{array}$ & PSNR(db) \\
\hline $\begin{array}{l}\text { Baboon.jpg } \\
\text { Fig 4(a) }\end{array}$ & $\begin{array}{l}\text { 1 point of insertion, P22 } \\
\text { \{sup\}, Fig 4(b) }\end{array}$ & 0 \\
\hline Baboon.jpg, Fig 4(a) & $\begin{array}{l}\text { 2 points of insertion, P22\{inf, } \\
\text { sup\}, Fig 4(c) }\end{array}$ & 0 \\
\hline Baboon.jpg, Fig 4(a) & $\begin{array}{l}\text { 3 points of insertion, P22\{inf, } \\
\text { sup\} \& P21 \{sup\}, Fig 4(d) }\end{array}$ & 42.1102 \\
\hline Lena.jpg, Fig 5(a) & $\begin{array}{l}\text { 1 point of insertion, P22 } \\
\text { \{sup\}, Fig 5(b) }\end{array}$ & 0 \\
\hline Lena.jpg, Fig 5(a) & $\begin{array}{l}\text { 2 points of insertion, P22\{inf, } \\
\text { sup\}, Fig 5(c) }\end{array}$ & 0 \\
\hline Lena.jpg, Fig 5(a) & $\begin{array}{l}\text { 3 points of insertion, P22\{inf, } \\
\text { sup\}, \& P21 \{sup\}, Fig 5(d) }\end{array}$ & 0 \\
\hline Peppers.jpg, Fig 6(a) & $\begin{array}{l}\text { 1 point of insertion, P21\{inf\}, } \\
\text { Fig 6(b) }\end{array}$ & 18.0533 \\
\hline Peppers.jpg, Fig 6(a) & $\begin{array}{l}\text { 2 points of insertion, P21\{inf, } \\
\text { sup\}, Fig 6(c) }\end{array}$ & 18.0533 \\
\hline Peppers.jpg, Fig 6(a) & $\begin{array}{l}\text { 3 points of insertion, P21 \{inf, } \\
\text { sup\} \& P22[sup\}, Fig 6(d) }\end{array}$ & 17.7247 \\
\hline
\end{tabular}

PSNR is Peak Signal to Noise Ratio between original image and watermarked image is given by

PSNR $=10 \log _{10}\left(\mathrm{X}_{\text {max }}^{2} / \mathrm{MSE}\right)$

Where $\mathrm{X}_{\max }$ : is maximum luminance. $\mathrm{B}$ bit per sample has $\mathrm{X}_{\max }$ equal to $2^{\mathrm{B}}-1$.

MSE is mean-square-error between original image and watermarked image given by

$$
\mathrm{MSE}=\sum_{\mathrm{i}=1}^{\mathrm{N}} \sum_{\mathrm{j}=1}^{\mathrm{M}}\left(\mathrm{I}_{\mathrm{ij}}-\mathrm{J}_{\mathrm{ij}}\right)^{2} / \mathrm{NM}
$$

Where $\mathrm{N} X \mathrm{M}$ pixels of original image $\mathrm{I}$ and watermarked Image $\mathbf{J}$.

\section{CONCLUSION AND FUTURE SCOPE OF WORK}

The digital images are watermarked with encrypted files in order to have invisible watermark. The watermark are encrypted and decrypted to see the image is authentic or it is tried to tamper. The above method is robust as the key used as public key does not lead to any clue for private key. The public key is fuzzy matrix chosen by user and private key is the Fuzzy Rough set for embedded watermark. The four or more parts of files can embedded into image in the respective region using appropriate Fuzzy Rough set to get desired results. It can tolerate attacks like compression, geometric filters and noise filters. The watermark is robust against changes in file format. These embedding methods can be used for all file formats. The watermark is extracted and decrypted using private key by other party. Further, the work is to be extended for achieving robustness and restraining many more types of attacks.

\section{REFERENCES}

[1] A. Menezes, P. van Oorschot, and S. Vanstone, "Handbook of Applied Cryptography", CRC Press, 1996.

[2] An Introduction to Cryptography, 1999 Network Associates, Inc. and its Affiliated Companies. 
[3] Glenn Durfee, $\mathrm{PhD}$ thesis "Cryptanalysis Of RSA Using Algebraic And Lattice Methods", June 2002, Stanford University.

[4] Alina Mihaela Oprea ,"Efficient Cryptographic Techniques for Securing Storage Systems" CMU-CS-07-119April 2007, PhD thesis, School of Computer Science Carnegie Mellon University ,Pittsburgh, PA 15213.

[5] Shafi Goldwasser, Mihir Bellare,"Lecture Notes on Cryptography", MIT,July 2008.

[6] Whitefiled Diffie and Martin E. Hellman , "Multiuser Cryptographic Techniques*”, Stanford University Stanford, California.

[7] Kenneth W. Dam and Herbert S. Lin, "Cryptography's Role in Securing the Information Society", Editors, Committee to Study National Cryptography Policy, National Research Council.

[8] Harvey Cohn, "Advanced Number Theory", Distinguished Professor, City University New York.

[9] Rethinking Public Key Infrastructures and Digital Certificates, Rethinking Public Key Infrastructures and Digital Certificates, MIT PressR.

[10] Benny Pinkas, "Cryptographic Techniques for Privacy Preserving Data Mining”, HP Labs, benny.pinkas@hp.com

[11] Sharbani Bhattacharya, "Data Security :Issue in Cloud Computing for e-Learning", Published in University School of Management Studies ,Guru Govind Singh Indraprastha University in National Conference on Information Management $20^{\text {th }}$ March 2010 on. Conference proceedings \& Book in - "Information Management in Knowledge Economy", MacMillan Publishers Page 165.

[12] Xinyuan Wang and Douglas S. Reeves "Robust Correlation of Encrypted Attack Traffic Through Stepping Stones By Watermarking The Interpacket Timing", Dept. of Computer Science ,North Carolina State University, Raleigh, NC 27695.

[13] E. C. C. Tsang, Changzhong Wang, Degang Chen, Congxin Wu and Qinghua Hu, "Communication Between Information Systems Using Fuzzy Rough Sets", IEEE Transactions On Fuzzy Systems, Vol. 21, No. 3, June 2013, Page 527.

[14] Teresa Garcia-Valverde, Alberto Garcia-Sola, Hani Hagras, James A. Dooley,Victor Callaghan and Juan A. Botia, "A Fuzzy Logic-Based System for Indoor Localization Using WiFi in Ambient Intelligent Environments", IEEE Transactions On Fuzzy System, Vol. 21, No. 4, August 2013, Page 702.

[15] Hooman Tahayori, Alireza Sadeghian and Witold Pedrycz, "Induction of Shadowed Sets Based on the Gradual Grade of Fuzziness", ", IEEE Transactions On Fuzzy System, Vol. 21, No. 5, October 2013,Page 937.

[16] S.P.Tiwari and Arun K.Srivastava,"Fuzzy rough sets,fuzzy preorders and fuzzy topologies", Elsevier, Fuzzy Sets and Systems, Vol. 210 ,2013,Page 63.

[17] Dong Zheng, Yan Liu, Jiyang Zhao, and Abdulmotelab El Sadikk , "A Survey of RST Invariant Image Watermarking Algorithms" , ,University of Ottawa ACM Computing Surveys", Vol. 39, No. 2, Article 5, Publication date: June 2007.
[18] Sameh Oueslati, Adnane Cherif and Basel Solaiman, "A Fuzzy Watermarking Approach Based on the Human Visual System", page 218, International Journal Of Image Processing, Volume (4): Issue (3). 2010.

[19] Anderson Rocha, Walter Scheirer and Terrance Boult, Siome Goldenstein, "Vision of the Unseen: Current Trends and Challenges in Digital Image and Video Forensics" ACM Computing Surveys, Vol. 43, No. 4, Article 26, Publication date: October 2011.

[20] Chuntao WangJiangqun $\mathrm{Ni}$,and Jiwu, "An Informed Watermarking Scheme Using Hidden Markov Model in the Wavelet Domain" Huang,IEEE Transactions On Information Forensics And Security, Vol. 7, No. 3, June 2012 , Page853.

[21] J. C. Kelkboom, Jeroen Breebaart, Ileana Buhan, and Raymond N. J.Veldhuis, "Maximum Key Size and Classification Performance of Fuzzy Commitment for Gaussian Modeled Biometric Sources" IEEE Transaction On Information Forensic and Security, Vol. 7, No. 4, August 2012 Page No. 122.

[22] Peyman Rahmati, Andy Adler and Thomas Tran , "Watermarking in E-commerce", International Journal of Advanced Computer Science and Applications, Vol. 4, No. 6, 2013.

[23] T.Sridevi and S Sameena Fatima,"Digital Image Watermarking using Fuzzy Logic approach based on DWT and SVD”, International Journal of Computer Applications, Vol 74- No.13, July 2013.

[24] Mriganka Gogoi , H.M.Khalid Raihan Bhuyan ,Koushik Mahanta , Dibya Jyoti Das and Ankita Dutta, " Image and Video based double watermark extraction spread spectrum watermarking in low variance region", International Journal of Advanced Computer Science and Applications, Vol. 4, No. 6, July 2013.

[25] Sharbani Bhattacharya, "Encrypting Watermark by Fuzzy Max-Min Matrix" presented in National Conference on Advances in Mobile Communications, Networking and Computing, MCNC 2013, ICEIT Conference on 27 -28 September 2013 at IIC, Lodhi Road, New Delhi published in Conference Proceedings, Page 150

[26] Alimohammad Latif, “ An Adaptive Digital Image Watermarking Scheme using Fuzzy Logic and Tabu Search", Journal of Information Hiding and Multimedia Signal Processing, Volume 4, Number 4, October 2013.

[27] Elzbieta Zielinska, Wojciech Mazurczyk and Krzysztof Szczypiorski, "Trends in Steganography", Communication of ACM, Vol 57 ,No. 3, March 2014.

[28] Qian Ying, Ren Xue-mei, Huang Ying and Meng Li, “ Image Sharpness Metric Based on Algebraic Multi- Grid Method",International Journal of Advanced Computer Science and Applications, Vol. 5, No. 4,April 2014.

[29] Sharbani Bhattacharya, "Watermarking Digital Image Using Fuzzy Matrix Rules", presented in National Conference Smarter Approaches in Computing, Technology \& Applications SACTA 2014 at ITS ,Mohan Nagar, Ghaziabad $19^{\text {th }}$ April 2014, published in Conference Proceedings Page No 343 . 